\title{
Suture retraction technique to prevent parent vessel obstruction following aneurysm tandem clipping
}

\author{
Tarek Rayan, MD, and Sepideh Amin-Hanjani, MD \\ Department of Neurosurgery, University of Illinois at Chicago, Illinois
}

With large or giant aneurysms, the use of multiple tandem clips can be essential for complete obliteration of the aneurysm. One potential disadvantage, however, is the considerable cumulative weight of these clips, which may lead to kinking of the underlying parent vessels and obstruction of flow. The authors describe a simple technique to address this problem, guided by intraoperative blood flow measurements, in a patient with a ruptured near-giant $2.2 \times 1.7-\mathrm{cm}$ middle cerebral artery bifurcation aneurysm that was treated with the tandem clipping technique. A total of $11 \mathrm{clips}$ were applied in a vertical stacked fashion. The cumulative weight of the clips caused kinking of the temporal $\mathrm{M}_{2}$ branch of the bifurcation with reduction of flow. A 4-0 Nurolon suture tie was applied to the hub of one of the clips and was tethered to the dura of the sphenoid ridge by a small mini-clip and reinforced by application of tissue sealant. The patient underwent intraoperative indocyanine green videoangiography as well as catheter angiography, which demonstrated complete aneurysmal obliteration and preservation of vessel branches. Postoperative angiography confirmed patency of the bifurcation vessels with mild vasospasm. The patient had a full recovery with no postoperative complications and was neurologically intact at her 6-month follow-up. The suture retraction technique allows a simple solution to parent vessel obstruction following aneurysm tandem clipping, in conjunction with the essential guidance provided by intraoperative flow measurements.

http://thejns.org/doi/abs/10.3171/2014.9.JNS141547

KEY WORDS clip; flow measurement; giant aneurysm; middle cerebral artery; vascular disorders; surgical technique; tandem clipping

$\mathrm{W}$ ITH large or giant aneurysms, the use of multiple tandem clips can be essential for complete obliteration of the aneurysm neck. ${ }^{9}$ One disadvantage of this technique, however, is the considerable cumulative weight of these clips, potentially leading to kinking of the underlying parent vessels. We illustrate a simple technique that can be useful in addressing this problem, guided by intraoperative blood flow measurements.

\section{Technical Case Report Clinical Presentation}

A 47-year-old woman, with no medical history, presented with a Hunt and Hess Grade II subarachnoid hemorrhage $(\mathrm{SAH})$ from a ruptured near-giant $2.2 \times 1.7-\mathrm{cm}$ middle cerebral artery (MCA) bifurcation aneurysm (Fig. 1). During surgery, appreciation of the complex aneurysm configuration and significant neck atheroma required vertical stacking of multiple clips in tandem to allow obliteration of the aneurysmal sac with reconstruction of the MCA bifurcation. A total of 11 clips were ultimately applied, using primarily fenestrated clips to maximize the closing force along the clip blades (Video 1).

VIDEO 1. Narrated operative video depicting the suture retraction technique for alleviating $\mathrm{M}_{2}$ branch vessel obstruction following tandem clipping of an MCA aneurysm. Copyright Sepideh AminHanjani. Published with permission. Click here to view with Media Player. Click here to view with Quicktime.

During clipping, intraoperative flow measurements with an ultrasonic microvascular flow probe (Charbel MicroFlowprobe, Transonic Systems Inc. $)^{1}$ demonstrated a significant reduction of flow in the temporal $\mathrm{M}_{2}$ branch of the bifurcation, from a baseline flow measurement of 55 $\mathrm{ml} / \mathrm{min}$ to $14 \mathrm{ml} / \mathrm{min}$. This was felt to be attributable to

ABBREVIATIONS ICA = internal carotid artery; MCA = middle cerebral artery; $\mathrm{SAH}=$ subarachnoid hemorrhage.

SUBMITTED July 8, 2014. ACCEPTED September 10, 2014.

INCLUDE WHEN CITING Published online February 27, 2015; DOI: 10.3171/2014.9.JNS141547.

DISCLOSURE The authors report no conflict of interest concerning the materials or methods used in this study or the findings specified in this paper. 


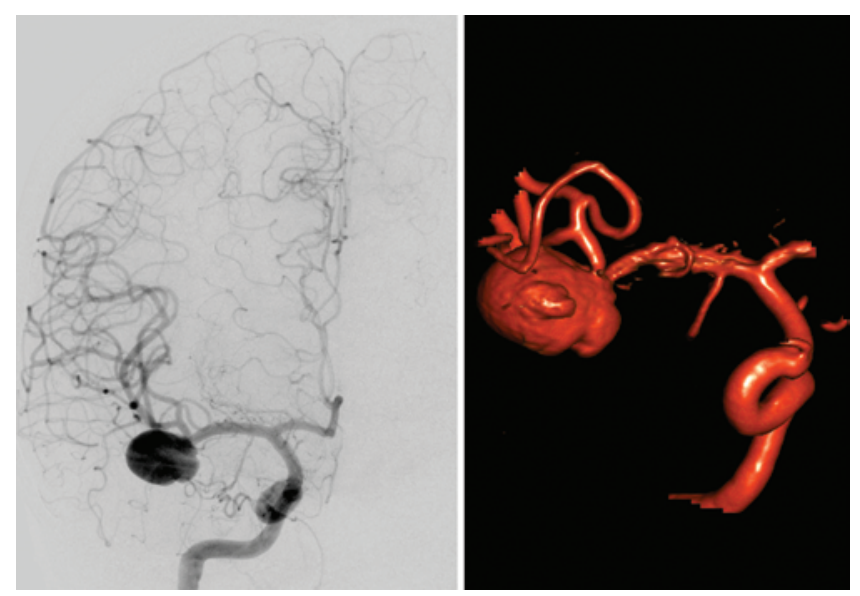

FIG. 1. Left: Preoperative right internal carotid artery (ICA) digital subtraction angiogram (anteroposterior view) demonstrating a large right MCA aneurysm. Right: Preoperative right ICA 3D angiography view of the MCA aneurysm. Figure is available in color online only.

a kink in the parent artery caused by the weight of the stacked clips. This impression was confirmed by reproducible improvement in flow toward baseline levels upon gentle lifting of the clip complex away from the temporal $\mathrm{M}_{2}$ segment toward the sphenoid ridge, along with visible resolution of the previously noticed kink.

\section{Technique}

To relieve the kink, a 4-0 Nurolon suture tie (ETHICON Inc.) was applied to the hub of one of the fenestrated clips and tethered to the dura of the sphenoid ridge by a small securing mini-clip (Figs. 2 and 3). The suture was successful in lifting the aneurysm dome and stacked clips away from the MCA bifurcation, and restoring patency and flow in the $\mathrm{M}_{2}$ branch.

After confirmation of adequate and stable flows in the artery, the attachment site of the suture was reinforced by application of tissue sealant (TISSEEL, Baxter Healthcare Corp.), which was also used to maintain dural adherence to the overlying sphenoid bone, to maintain the anterior
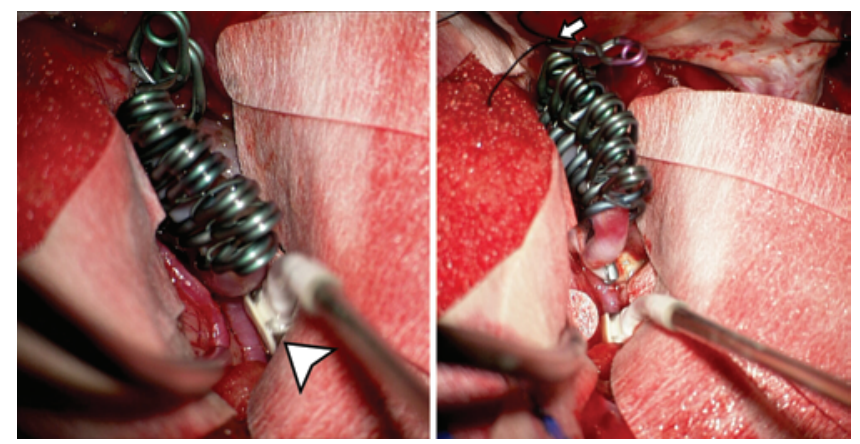

FIG. 2. Left: Intraoperative photograph of the tandem clipping configuration causing kinking of the $\mathrm{M}_{2}$ temporal bifurcation branch due to cumulative weight of the applied clips. The microflow probe is being placed around the temporal $\mathrm{M}_{2}$ branch (arrowhead). Right: Intraoperative photograph after applying the suture retraction technique (arrow), lifting the weight of the clip complex off the $\mathrm{M}_{2}$ temporal branch. Flow measurement in the temporal $\mathrm{M}_{2}$ branch is demonstrated, which confirmed restoration of flow. Figure is available in color online only.
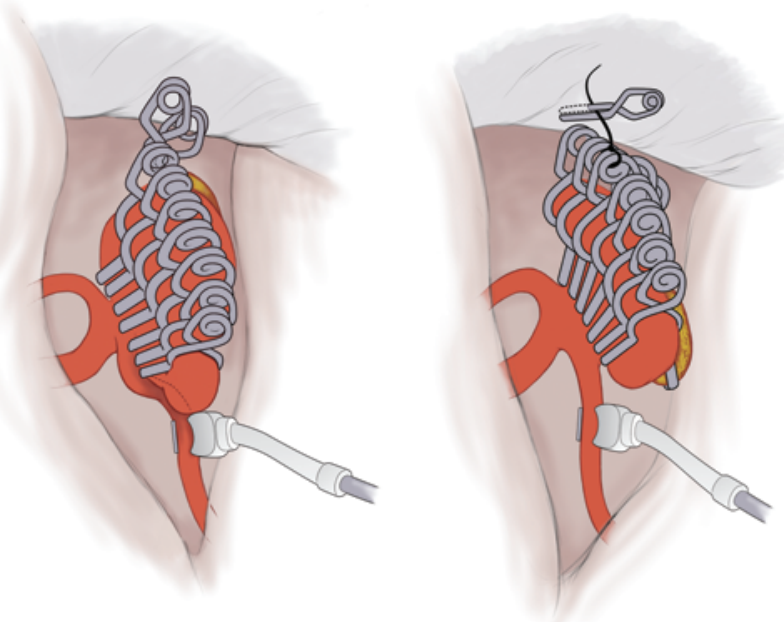

FIG. 3. Left: Illustration showing the initial tandem clip configuration causing a kink in the underlying $\mathrm{M}_{2}$ temporal bifurcation branch. Right: Illustration showing the tandem clip and aneurysm configuration after applying the suture retraction technique, lifting it away from the underlying $\mathrm{M}_{2}$ temporal branch. Copyright Sepideh Amin-Hanjani. Published with permission. Figure is available in color online only.

displacement of the clip complex. During closure, the dural edges were not reapproximated to avoid disrupting the dural adherence to the sphenoid bone anteriorly; the dural flap was placed gently back on the brain surface, and the remaining exposed brain was covered with a dural substitute prior to replacement of the bone flap.

\section{Outcome}

The patient underwent indocyanine green videoangiography and intraoperative angiography following replacement of the cranial bone flap, which demonstrated complete aneurysm obliteration and preservation of vessel branches. Postoperative angiography on Day 7 confirmed no residual and mild vasospasm (Fig. 4). The patient made a full recovery post-SAH with no postoperative complications and was neurologically intact at the time of her 6-month follow-up. Head CT scanning postoperatively
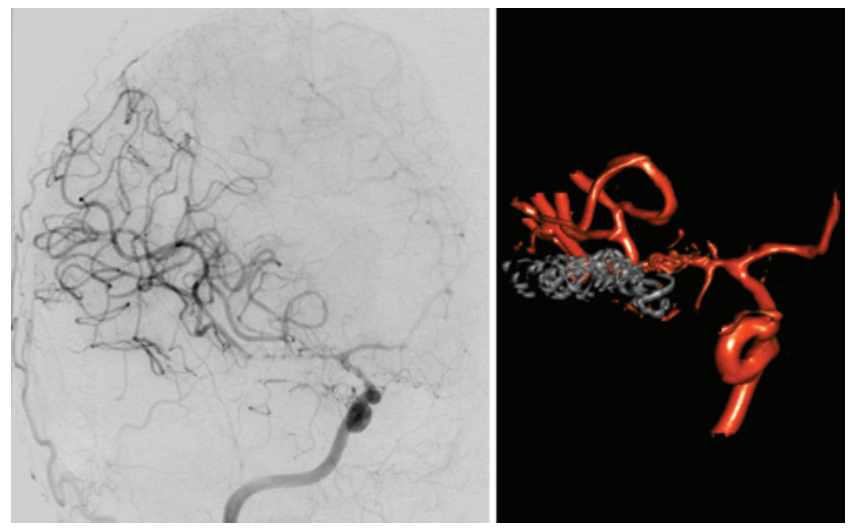

FIG. 4. Left: Postoperative right ICA digital subtraction angiogram (anteroposterior view) demonstrating complete obliteration of the right MCA aneurysm, with patent MCA branches. Right: Postoperative right ICA $3 \mathrm{D}$ angiography view of the clip configuration. Figure is available in color online only. 
and at 6 months demonstrated stability of the securing clip against the sphenoid ridge (Fig. 5).

\section{Discussion}

The configuration and complexity of MCA bifurcation aneurysms can necessitate a variety of different clipping strategies..$^{3-5,7}$ In the setting of large or giant aneurysms, complete obliteration with reconstruction of parent arteries can be a difficult task, especially in the setting of associated atheroma. Tandem clipping is an efficient technique to obliterate the aneurysm in such cases, using fenestrated clips, which can exert uniform closing force along the clip blades to more successfully compress the aneurysm dome. ${ }^{9}$ A potential disadvantage, however, is the cumulative weight of the applied clips causing a kink in the underlying vessels, with subsequent flow compromise.

The technique described herein allows a simple solution to this problem. Strategies for manipulation of the location of intracranial vessels have been previously described using slings or suture material tethered to the dura. ${ }^{6,8}$ The use of suture tied to a fenestrated clip encircling a vessel, for purposes of transposing it during microvascular decompression, has also been described. ${ }^{2}$ In this report, we adapt the same concept to relieve the weight of multiple clips applied to an aneurysm dome, thus preventing parent vessel compromise. The suture attached to one of the multiple clip hubs was clipped rather than tied to the adjacent dura for easier maneuverability and readjustment (see Video 1). In conjunction with the essential guidance provided by intraoperative flow measurements, the tension on the suture could be adjusted to allow optimal displacement of the clip complex to relieve vessel kinking at the aneurysm base. The immediate feedback provided by the intraoperative flow measurement and the assurance of restored baseline flow levels after resolution of kinking were important adjuncts to the success of this strategy.

\section{Conclusions}

The suture retraction technique allows a simple solution to parent vessel obstruction following aneurysm tandem clipping, in conjunction with the essential guidance provided by intraoperative flow measurements.
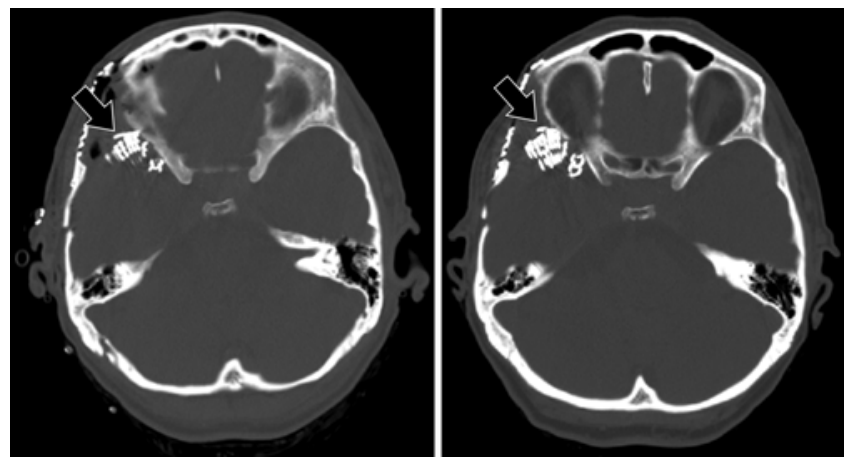

FIG. 5. Left: Postoperative head CT scan demonstrating the securing clip adjacent to the flattened sphenoid ridge (arrow). Right: Follow-up head CT scan at 6 months demonstrating the stability of the securing clip (arrow).

\section{Acknowledgment}

We would like to acknowledge Christa Wellman for assistance with the illustrative figures in this manuscript.

\section{References}

1. Amin-Hanjani S, Meglio G, Gatto R, Bauer A, Charbel FT: The utility of intraoperative blood flow measurement during aneurysm surgery using an ultrasonic perivascular flow probe. Neurosurgery 62 (6 Suppl 3):1346-1353, 2008

2. Attabib N, Kaufmann AM: Use of fenestrated aneurysm clips in microvascular decompression surgery. Technical note and case series. J Neurosurg 106:929-931, 2007

3. Clatterbuck RE, Galler RM, Tamargo RJ, Chalif DJ: Orthogonal interlocking tandem clipping technique for the reconstruction of complex middle cerebral artery aneurysms. Neurosurgery 59 (4 Suppl 2):ONS347-ONS352, 2006

4. Dashti R, Hernesniemi J, Niemelä M, Rinne J, Porras M, Lehecka M, et al: Microneurosurgical management of middle cerebral artery bifurcation aneurysms. Surg Neurol 67:441456, 2007

5. Kato Y, Sano H, Imizu S, Yoneda M, Viral M, Nagata J, et al: Surgical strategies for treatment of giant or large intracranial aneurysms: our experience with 139 cases. Minim Invasive Neurosurg 46:339-343, 2003

6. Masuoka J, Matsushima T, Kawashima M, Nakahara Y, Funaki T, Mineta T: Stitched sling retraction technique for microvascular decompression: procedures and techniques based on an anatomical viewpoint. Neurosurg Rev 34:373-380, 2011

7. Sano H: Treatment of complex intracranial aneurysms of anterior circulation using multiple clips. Acta Neurochir Suppl 107:27-31, 2010

8. Shigeno T, Kumai J, Endo M, Oya S, Hotta S: Snare technique of vascular transposition for microvascular decompression-technical note. Neurol Med Chir (Tokyo) 42:184190, 2002

9. Yang I, Lawton MT: Clipping of complex aneurysms with fenestration tubes: application and assessment of three types of clip techniques. Neurosurgery 62 (5 Suppl 2):ONS371ONS379, 2008

\section{Author Contributions}

Conception and design: Amin-Hanjani. Acquisition of data: both authors. Analysis and interpretation of data: Amin-Hanjani. Drafting the article: both authors. Reviewed submitted version of manuscript: both authors. Approved the final version of the manuscript on behalf of both authors: Amin-Hanjani. Administrative/technical/material support: Rayan. Study supervision: AminHanjani.

\section{Supplemental Information \\ Videos}

Video 1, Media Player. http://mfile.akamai.com/21490/wmv/ digitalwbc.download.akamai.com/21492/wm.digitalsource-naregional/jns14-1547_video_1.asx.

Video 1, Quicktime. http://mfile.akamai.com/21488/mov/ digitalwbc.download.akamai.com/21492/qt.digitalsource-global/ jns14-1547_video_1.mov.

\section{Correspondence}

Sepideh Amin-Hanjani, Department of Neurosurgery, University of Illinois at Chicago, Neuropsychiatric Institute, Rm. 451N, 912 S. Wood St., M/C 799, Chicago, IL 60612. email: hanjani@uic. edu. 